\title{
The European 2MW, 170GHz Coaxial Cavity Gyrotron for ITER
}

\author{
J.-P. Hogge ${ }^{1}$, F. Albajar ${ }^{5}$, S. Alberti ${ }^{1}$, P. Benin ${ }^{4}$, T. Bonicelli ${ }^{5}$, S. Cirant ${ }^{6}$, D. Fasel ${ }^{1}$, T. Goodman ${ }^{1}$, S. Illy ${ }^{2}$, \\ S. Jawla ${ }^{1}$, C. Lievin ${ }^{4}$, I. Pagonakis ${ }^{1}$, A. Perez ${ }^{1}$, B. Piosczyk ${ }^{2}$, L. Porte ${ }^{1}$, T. Rzesnicki ${ }^{2}$, M. Thumm ${ }^{2,3}$, M.Q. Tran ${ }^{1}$
}

\begin{abstract}
In the reference ECH design, ITER requires a total of $20 \mathrm{MW} / \mathrm{CW}$ power at $170 \mathrm{GHz}$ using gyrotrons with a unit power of $1 \mathrm{MW}$. A higher power per unit (2MW/gyrotron) would result in a strong reduction of the cost of the whole ECRH system, and would also relax the room constraints on the launcher antenna design. The high power capability of coaxial cavity gyrotrons has been demonstrated with short pulse experiments at FZK. A collaborative effort between European research associations CRPP-EPFL, FZK and Thales Electron Devices (TED) has been launched by the European Fusion Development Agreement (EFDA) in 2003, aiming at the development of an industrial $170 \mathrm{GHz} / 2 \mathrm{MW} / \mathrm{CW}$ coaxial cavity gyrotron. The first prototype, although designed to be $\mathrm{CW}$ compatible is expected to reach $2 \mathrm{MW} / 1 \mathrm{~s}$ and has been delivered by end of 2006. It will be tested in Lausanne, where a specially dedicated test facility has been built. The test facility has been designed to be flexible enough, allowing the possible commissioning of tubes with different characteristics, as well the tests of the launcher antenna at full performances. Initial experiments are planned for the end of the third quarter 2007.
\end{abstract}

Index Terms-Coaxial cavity gyrotron, ITER

\section{INTRODUCTION}

$\mathbf{I}$ $\mathrm{T}$ has been shown in the past that coaxial gyrotrons offer a serious alternative to conventional gyrotrons in the perspective of increasing the unit power to multi-megawatt levels, in a frequency range compatible with the ITER requirements [1]. The inner conductor combines the advantages of mode selectivity and a minimisation of the beam depression, making it possible to maintain the cavity ohmic losses at a reasonably low level $\left(<2 \mathrm{~kW} / \mathrm{cm}^{2}\right)$ by increasing the cavity diameter and selecting a very high order operation mode.

Based on these considerations, the coaxial option was chosen by the European Fusion Development Agreement (EFDA), which launched a collaboration between European institutions and a commercial partner (Thales Electron Devices, TED) aiming at the development of a $2 \mathrm{MW} / \mathrm{CW} / 170 \mathrm{GHz}$ coaxial gyrotron in three steps: the first prototype tube is aiming at

\footnotetext{
${ }^{1}$ Centre de Recherche en Physique des Plasmas, Association EURATOMConfédération Suisse, Ecole Polytechnique Fédérale de Lausanne,CH-1015 Lausanne, Switzerland

${ }^{2}$ Forschungszentrum Karlsruhe, Association EURATOM-FZK, Institut für Höchleistungsimpuls- und Mikrowellentechnik

${ }^{3}$ Universität Karlsruhe, Institut für Höchstfrequenztechnik und Elektronik, Kaiserstr. 12, D-76128 Karlsruhe, Germany

4 Thales Electron Devices, 2 Rue de Latécoère, F-78141 VélizyVillacoublay, France

${ }^{5}$ European Fusion Development Agreement, Boltzmannstrasse 2, D-85748 Garching bei Muenchen, Germany

${ }^{6}$ Instituto di Fisica del Plasma Consiglio Nazionale delle Ricerche, Via Cozzi 53, I-20125 Milano, Italy
}

a performance of $2 \mathrm{MW} / 1 \mathrm{~s}$, the second one will be targeting $2 \mathrm{MW} / 60$ s after a possible redesign phase, and the third prototype is expected to reach $\mathrm{CW}$ operation. The prototype tubes will be tested on the newly built CRPP test stand, which is operational and offers the possibility to characterise the tube at full performance. In parallel, the FZK $165 \mathrm{GHz}$ short pulse coaxial tube has been modified to operate as a "pre-prototype" at $170 \mathrm{GHz}$, with internal components very similar to the actual design, giving the possibility to test the different scientific or technical options envisaged in a high power environment, such as the use of internal water loads, the effect of stray radiation on the interaction and the the study of low-frequency oscillations [3].

In section II, the gyrotron design parameters are briefly summarized, with emphasis on different key aspects related to the high power and long pulse operation. The section III gives an account of the project status, and the future prospects are listed in section IV.

\section{GYROTRON DESCRIPTION}

The gyrotron has been extensively described elsewhere [2] A sketch of the tube is represented on Figure 1, and the main parameters are summarised on Table I. A few key features are listed below:

- The tube has been designed to be CW compatible. In particular, a set of internal loads consisting in watercooled ceramic tubes has been implemented. Such loads have been proven efficient in absorbing stray radiation on the short pulse pre-prototype.

- The alignment of the coaxial insert will be performed at reduced parameters with the help of dipole coils located in the superconducting magnet, allowing to radially move the electron beam until an interception current is measured.

- The present RF output system consists in a launcher with $\Delta m=2$ and $\Delta m=3$ perturbations. The last mirror has a non-quadratic surface in order to minimize the amount of radiation reflected back in the tube, at the cost of gaussian content [3]. An improvement of the RF output beam quality is necessary and is under intensive study. An updated RF output system will already be implemented on the first prototype, once refurbished (see section IV).

- Most of the subassemblies, including the beam duct, the cavity, the RF output system and the mirror box are at the depressed voltage $(+35 \mathrm{kV})$. A DC-Break is used between the output window and the RF Conditioning Unit (RFCU). 
- The RFCU consists in 1 tiltable mirror which compensates for a possible misalignment of the RF beam, 2 quadratic mirrors, and 2 gratings forming a universal polarizer.

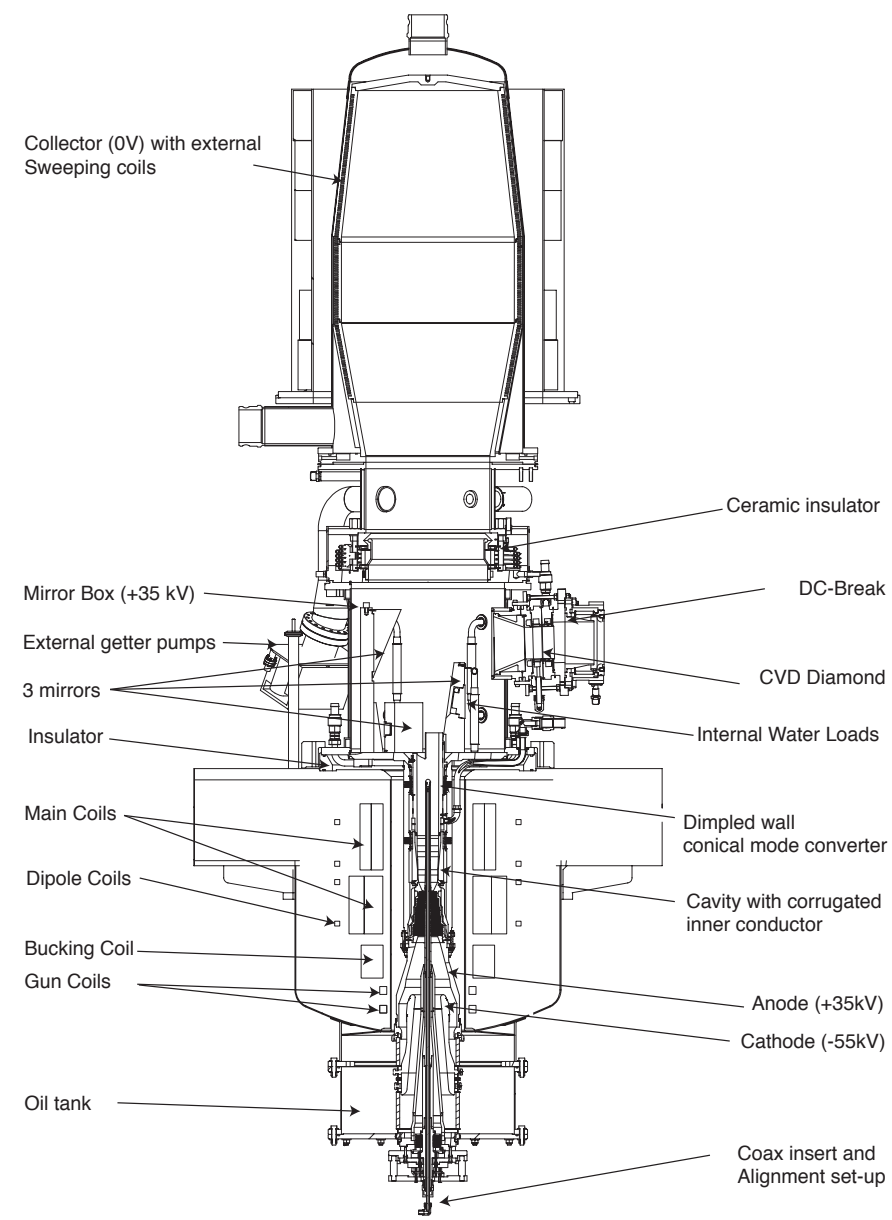

Fig. 1. Sketch of the $2 \mathrm{MW} / \mathrm{CW} 170 \mathrm{GHz}$ gyrotron

\section{STATUS OF THE PROJECT}

\section{A. First Prototype Tube}

The first prototype tube has been delivered by end of 2006 with the RF Conditioning Unit (RFCU). Initial tests not requiring the SCM, such as high voltage stand-off properties and the validation of the cooling circuits were carried out successfully. The picture 2 shows the gyrotron installed in a dummy magnet in order to perform the above mentioned tests, and connected to RFCU and the short pulse load (blue sphere).

\section{B. Superconducting Magnet}

Due to technical problems, the superconducting magnet delivery has been delayed and is expected to take place during the summer 2007. A picture of the magnet during the initial cool down test is represented on figure 3 .
TABLE I

MAIN CHARACTERISTICS OF THE 2MW/170GHz/CW TUBE.

\begin{tabular}{lr}
\hline \hline Design Parameter & Value \\
\hline Frequency & $170 \mathrm{GHz}$ \\
Magnetic field & $6.86 \mathrm{~T}$ \\
Operating mode & $\mathrm{TE}_{34,19}$ \\
Cathode voltage & $-55 \mathrm{kV}$ \\
Body voltage & $+35 \mathrm{kV}$ \\
Beam current & $75 \mathrm{~A}$ \\
RF output power & $2 \mathrm{MW}$ \\
Power modulation & $0.6-2 \mathrm{MW}$ \\
Efficiency & $45 \%$ \\
Beam radius & $10 \mathrm{~mm}$ \\
Velocity ratio & 1.3 \\
Cavity peak losses & $1.7 \mathrm{~kW} / \mathrm{cm}^{2}$ \\
Cavity total losses & $45 \mathrm{~kW}$ \\
Insert peak losses & $.2 \mathrm{~kW} / \mathrm{cm}$ \\
Insert total losses & $2 \mathrm{~kW}$ \\
Stray radiation losses & $100 \mathrm{~kW}$ \\
Window & $\mathrm{CVD}$ diamond \\
Window diameter & $96 \mathrm{~mm}$ \\
Window losses & $880 \mathrm{~W}$ \\
Collector loading (CW) & $2.4 \mathrm{MW}$ \\
Collector loading (modulated operation) & $3.1 \mathrm{MW}$ \\
Single-stage depressed collector & - \\
Modulation frequency & $5 \mathrm{kHz}$ \\
& \\
\hline \hline
\end{tabular}

\section{Power Supplies}

The Body Power Supply (BPS) has been delivered and commissioned. The Main High Voltage Supply specifications have been updated, to include the possibility to perform the moodulation at the desired frequency. The deilvery is expected by beginning of 2008. In the mean time, an existing power supply $(85 \mathrm{kV} / 80 \mathrm{~A} / 10 \mathrm{~s})$, usually used to power part of the CRPP ECRH system will be used.

\section{Short Pulse load}

A short pulse load (2MW/100ms) has been designed, built, tested and delivered by CNR [4]. A CW compatible load, based on the same RF design, is under fabrication.

\section{E. Test Stand Infrastructure}

The Test Stand, including the mechanical, electrical and cooling infrastructure has been completed, as well as the Control and Data Acquisition System.

\section{PRospects}

The actual tests of the first prototype are expected to start by the end of the third quarter of 2007 and will last 9 months. The first series of experiments will aim at validating the coaxial gyrotron concept for pulses of the order of $1 \mathrm{~s}$, and extensively characterize its behaviour. The collector will eventually be tested at full performance. The tube will then be shipped back to TED, opened, carefully inspected, and finally be refurbished with an updated launcher and mirror system which should combine the positive effects of Gaussian content improvement and minimisation of the stray radiation losses. 


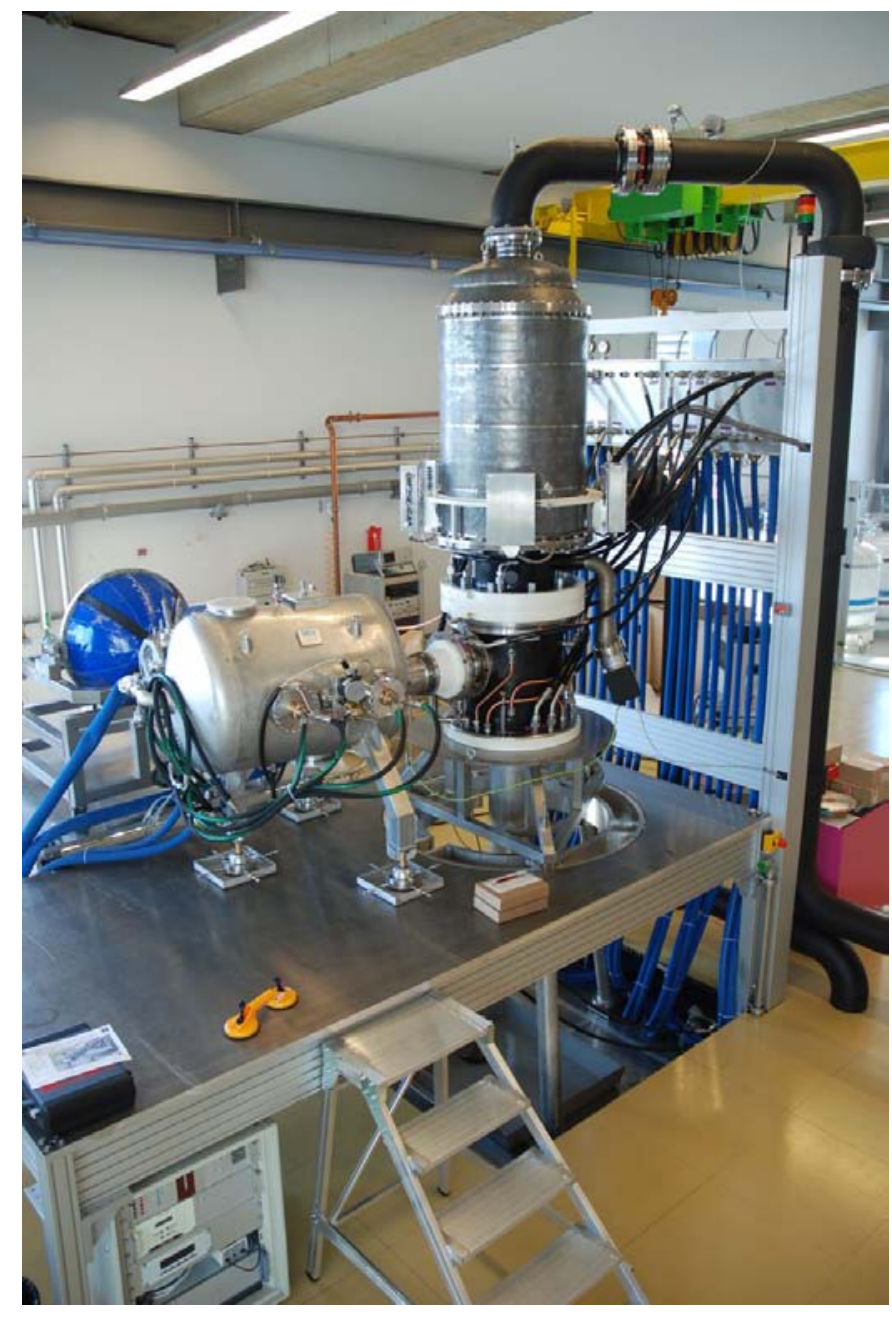

Fig. 2. Picture of the first prototype $170 \mathrm{GHz}$ gyrotron installed in a dummy magnet, with the the RFCU and the short pulse load.

\section{REFERENCES}

[1] B. Piosczyk et. al., "A 2-MW, 170-GHz, Coaxial Cavity Gyrotron", IEEE Trans. Plasma Science, 32, 2004, 413-417.

[2] J.-P. Hogge et.al., "Development of a 2-MW, Coaxial Gyrotron at 170GHz and Test Facility for ITER", Third IAEA Technical Meeting on "ECRH Physics and Technology for ITER", Como, Italy, 2005.

[3] B. Piosczyk et. al., "Investigations on an Experimental 170GHz Coaxial Cavity Gyrotron", this conference.

[4] A. Bruschi, W. Bin, S. Cirant et al., "High-Power Millimetre-Wave Calorimetric Beam Absorbers", accepted for publication on Fusion Science and Technology.

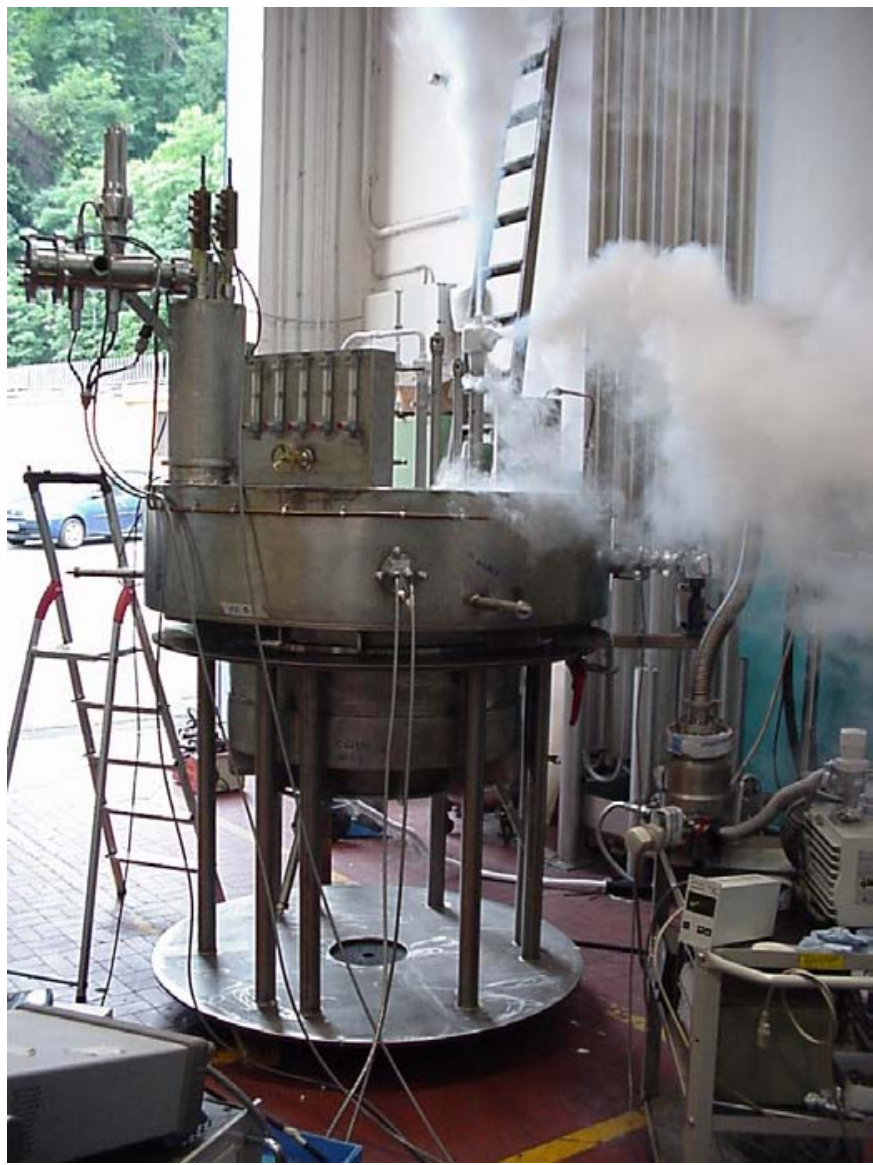

Fig. 3. Picture of the Superconducting Magnet during the factory tests. 